\section{Extreme events}

\section{Plants worsen flood risk}

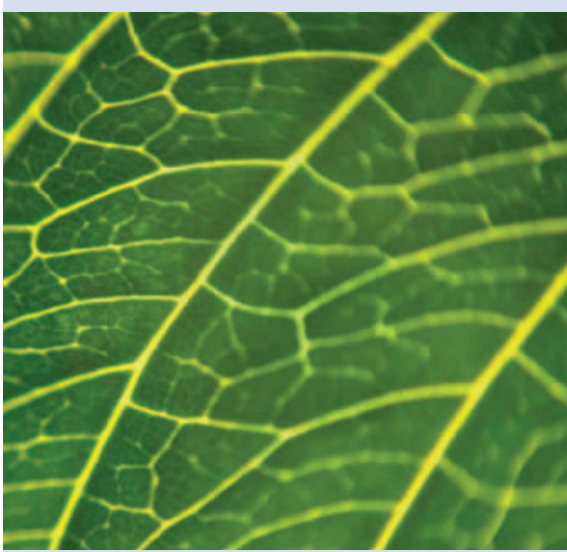

Nature 448, 1037-1041 (2007)

The response of plants to atmospheric carbon dioxide levels could drive increased continental water runoff in the future, finds a new study. Plant stomata open less widely under higher $\mathrm{CO}_{2}$ levels and therefore return less water directly to the atmosphere through the process known as transpiration. Therefore, more water remains at the land surface, contributing to continental runoff to rivers.

\section{Ocean science}

\section{Carbon consumers}

\section{Global Biogeochem. Cycles}

\section{doi:10.1029/2006GB002831 (2007)}

Bacteria growing in the low-salinity Amazon River plume waters, which stretch 3,000 km into the tropical Atlantic Ocean, are found to absorb significant amounts of $\mathrm{CO}_{2}$ from the atmosphere. Because tropical oceans are warm, they hold less dissolved carbon than oceans elsewhere and so typically emit $\mathrm{CO}_{2}$ to the atmosphere. But research now shows that communities of nitrogen-fixing bacteria, reliant on the nutrients contained in the Amazon river run-off, can shift the air-ocean balance so that instead of emitting $\mathrm{CO}_{2}$ the ocean absorbs it.

Sarah Cooley from the University of Georgia and colleagues measured levels of dissolved carbon in the Amazon River plume during April and May of 2003. Combining their observations of ocean and river composition with those from previous studies and with satellite observations of the plume, they calculated the total annual $\mathrm{CO}_{2}$ uptake by the plume waters.

They found the $\mathrm{CO}_{2}$ uptake, driven by bacterial consumption of carbon, to be about 15 million tonnes per year - emissions
Using 224 versions of a climate model, Richard Betts of the UK Met Office Hadley Centre and colleagues simulated the effect of doubled carbon dioxide concentrations on plant transpiration relative to that of preindustrial levels to assess the impact on runoff. They found that reduced plant transpiration resulting from rising carbon emissions has increased continental water runoff by $6 \%$ since 1860 , an increase comparable to that resulting from the direct impact of greenhouse gases on the water cycle.

The findings suggest that, because there will be more runoff to rivers, the risks of future flooding may be greater than previously thought. The researchers emphasize that greenhouse gases affect the climate through indirect means, such as this previously unquantified effect, as well as influencing the climate directly. They recommend that indirect effects should be accounted for in assessing future climate change.

Harvey Leifert

equivalent to about 20,000 return flights from London to Los Angeles. Carbon sequestration comes as a surprise in a region thought to emit $\mathrm{CO}_{2}$ to the atmosphere.

\section{Alex Thompson}

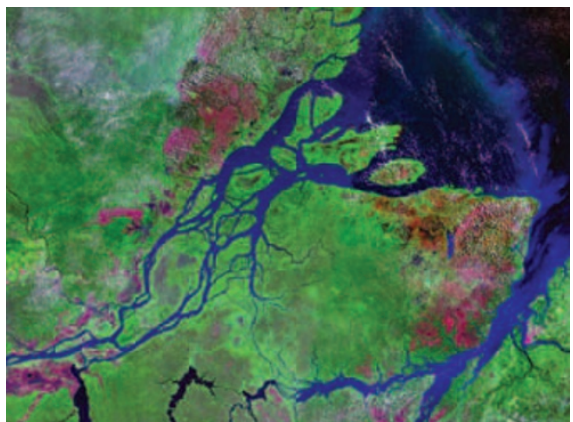

\section{Cryosphere}

\section{Permafrost protection}

Geophys. Res. Lett.34, L16504 (2007)

Permafrost, a layer of soil that remains at or below $0{ }^{\circ} \mathrm{C}$ for two or more years, may be buffered against the impacts of climate change by certain types of soil and vegetation. Melting permafrost has been implicated in damage to Arctic and sub-Arctic infrastructure, and as a possible source of methane, a greenhouse gas.

Shuhua Yi and colleagues at McMaster University, Ontario, used the Community Land Model Version 3 and historical climate records to simulate the depth of summer ground thaw at two sites in the Northwest Territories of Canada under a scenario of future warming. Although permafrost degradation was predicted for all sites in the 2000 to 2100 period, areas with mineral-based soil and no vegetation were most affected. Forest cover provided more protection than shrubs or bare ground, and thick layers of peat-rich soil were such effective insulators that permafrost showed only minimal decline even by 2100 .

Previous studies suggest that rising temperatures over the coming century would melt up to $90 \%$ of Northern Hemisphere permafrost, but these new results suggest the permafrost response will not be uniform. Extensive land management, including the preservation of forested and peat-rich areas, may be the key to maintaining permafrost into the future.

\section{Alicia Newton}

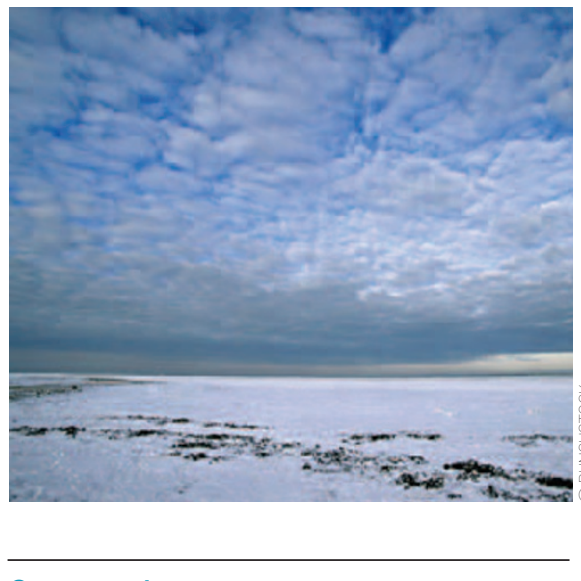

Ocean science

\section{Sea ice stabilizer}

\section{J. Clim. 20,4160-4171 (2007)}

As the world warms, melting sea ice will stabilize ocean circulation. The ocean thermohaline circulation, a major transporter of heat around the globe, determines much of our present climate. Because this circulation is driven by the sinking of cold dense waters in the northern North Atlantic, it is expected to decrease in strength as the surface ocean warms with climate change, and the extent to which this happens will depend on its initial strength.

Now, Anders Levermann and colleagues at the Potsdam Institute for Climate Impact Research in Germany propose a mechanism for climate-driven changes in the thermohaline circulation that involve the 
role of sea ice in retaining ocean heat. Based on the results of climate model simulations, they have found that as atmospheric temperatures increase with global warming, melting of sea ice allows more heat to be lost from the ocean, which in turn stabilizes the thermohaline circulation.

This previously unrecognized negative feedback mechanism between sea ice and the thermohaline circulation suggests that in a warmer world, ocean circulation may be more stable than previously thought.

\section{Alex Thompson}

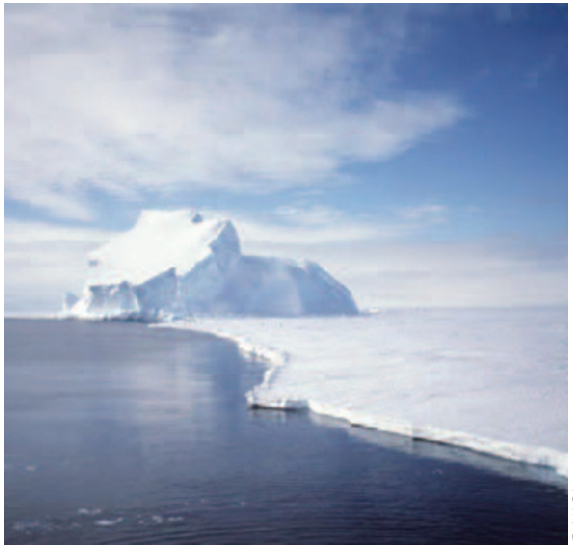

Atmospheric science

\section{Circulation slowdown}

J. Clim. 20, 4316-4340 (2007)

In the tropical Pacific region, air will probably circulate less vigorously in a warmer world, according to a new study. The expected changes resemble the effects of El Niño, a warming of the tropical Pacific surface ocean that occurs every 3 to 7 years and causes a shift in global weather patterns.

Gabriel Vecchi from the US National

Oceanic and Atmospheric Administration and Brian Soden from the University of Miami analysed simulations from 22 climate models that included a doubling of atmospheric $\mathrm{CO}_{2}$ by 2100 . The models agreed that the tropical Walker circulation - which lifts air over Indonesia that later descends towards Peru in a giant vertical loop - will slow down as the temperature increases. This change will arise from the response of the global water cycle to increased temperature and result in a climatic pattern similar to El Niño. But contrary to El Niño events, the ocean will respond to, rather than cause slowing of atmospheric overturning.

Climate models are still divided on whether El Niño years will become more frequent or intense. But they agree that in a warmer world, Pacific climate will be closer to today's El Niño years, implying a decline in nutrient delivery to the surface ocean and in fishstocks off Peru and Ecuador.

\section{Alex Thompson}

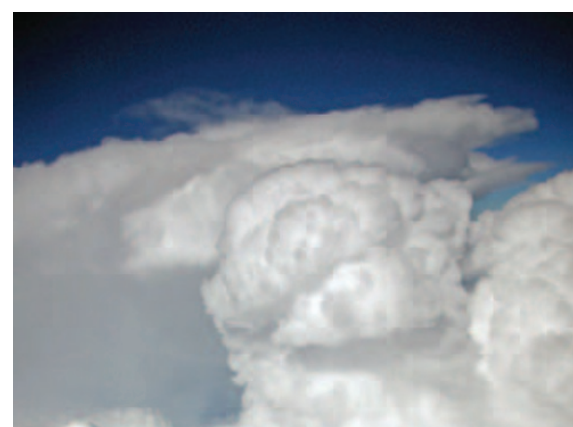

Biodiversity and ecology

\section{Root of the matter}

\section{Proc. R. Soc. B 274, 2753-2759(2007)}

According to a new study, the amount of carbon stored in plant roots could be almost $70 \%$ greater than previously thought.

David Robinson of the University of Aberdeen in the UK used a theoretical model combined with realistic measurements of root to shoot mass ratios to explore the implications of a revised global root carbon pool on estimates of global carbon sources and sinks. These are assessed using two methods: the global carbon flux, based on changes in atmospheric carbon dioxide, and the inventory method, based on land-use changes. The study predicted a pool of at least 268 petagrams ( $1 \mathrm{Pg}=1$ gigatonne), compared with previous estimates of about $160 \mathrm{Pg}$. On this basis, the land-based carbon sink is estimated at 2.7 Pg per year - 0.1 Pg per year greater than current estimates, suggesting it is stronger than previously recognized.

Alternatively, a larger root pool within existing global carbon budgets could mean that stocks of soil carbon are smaller than is thought and are depleting globally by up to $0.7 \%$ per year, possibly because of land-use change or climate change. This uncertainty highlights the urgent need to better understand the global carbon cycle to predict how it will respond to climate change.

Olive Heffernan

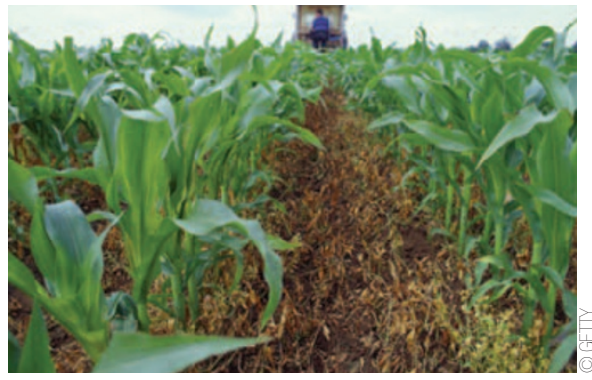

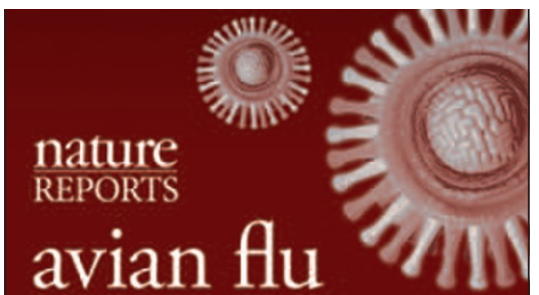

the news behind the science

the science behind the news

the seience behind the news

\section{Looking for avian flu research and latest news?}

\section{Add this link to your favourites: www.nature.com/reports/avianflu}

Nature Publishing Group has now assembled all of its articles, reports, commentary and news stories on avian flu and the $\mathrm{H} 5 \mathrm{~N} 1$ virus in one website.

Continually updated with any new material published, and with much of the content free access, Nature Reports Avian Flu is all you need to stay connected to the science behind the news on this potential pandemic.

www.nature.com/reports/avianflu

Produced with support from an unrestricted educational grant from GlaxoSmithKline Biologicals (Principal Sponsor)

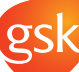

GlaxoSmithKline

and from Gilead Sciences (Supporting Sponsor)

\section{(1) GILEAD}

www.nature.com/reports/avianflu

nature publishing group npg 